\title{
The Potentials of a Maternal Mobile Wallet: a Qualitative Case Study on Opportunities and Challenges From Zimbabwe
}

\section{Zibusiso Nyati-Jokomo \\ Laurine Chikoko \\ Midlands State University \\ Liberty Makacha \\ Midlands State University \\ Newton Nyapwere \\ Midlands State University \\ Prestige Tatenda Makanga \\ Midlands State University}

University of Zimbabwe College of Health Sciences

Israel Mbekezeli Dabengwa ( $\square$ israel.dabengwa@nust.ac.zw )

Faculty of Medicine, National University of Science and Technology, Zimbabwe https://orcid.org/0000-0003-1160-8276

\section{Research article}

Keywords: Savings, Maternal Health, Pregnancy, Mobile Health Technology, Mobile Banking, Mobile Money Wallet, Maternal Health Mobile Wallet, Hyperinflation, Poverty, Zimbabwe

Posted Date: December 30th, 2020

DOI: https://doi.org/10.21203/rs.3.rs-135728/v1

License: (c) (i) This work is licensed under a Creative Commons Attribution 4.0 International License. Read Full License 


\section{Abstract}

Background: There are no systems put in place regarding mobile money for maternal savings in Zimbabwe. Therefore, this paper aims to highlight: (a) existing strategies and experiences about maternal savings in Kwekwe District and, (b) examine the implications of household dynamics and current savings behaviour towards the feasibility of implementing the RoadMApp Maternal Healthcare Mobile Wallet (MHMW).

Methods: Out of the 49 health facilities in Kwekwe, 2 hospitals (rural and urban), 4 rural health centres, 2 peri-urban, and 2 urban clinics were purposively selected for the study. Participants were recruited from these health facilities. 193 people took part in the study, through 11 Focus Group Discussions, 17 In-Depth Interviews, and 3 Community Meetings. The Socioecological Model's categories are applied to interpret the results taking into consideration the barriers and enablers of maternal savings.

Results: There is a paucity of information on strategies for maternal savings in Kwekwe District, Zimbabwe. The critical enabler for the implementation of an MHMW could be the use of existing community structures, like the burial societies and other savings clubs. Some of the essential barriers include low access to mobile phones, inadequate network coverage, power outages, a general lack of saving culture by communities, and the hyperinflationary environment in the country.

Conclusion: Although, the socio-economic status of households may be the best predictor of maternal savings, ancillary factors such as financial literacy, educational level, cultural norms, and religion will help to understand the psychosocial reasons why communities engage in maternal savings. When implementing an MHMW, specific attention should be paid to individual and community/institutional level factors such as subsidies/interests on amounts saved, enforcing financial discipline, building local level mobile network infrastructure, and relying on locally available persons/systems.

\section{Background}

The impediments to maternal savings amongst Zimbabwean women are financial barriers related to childbirth costs and general low saving culture (1). This has led to a high risk of childbirth complications, a high maternal mortality rate, and obstetric complications due to delays in care-seeking $(2,3)$. Savings are therefore essential as health costs may be unpredictable for populations that have no access to health insurance. In some cases, health insurance may have shortfalls besides the out of pocket (OOP) payments incurred by women when seeking maternal health care services.

The definition of what constitutes savings is normative and differs from one context to another. This paper sets the framework by defining it as resources which are not limited to money put into banks, but also assets that protect a person(s) from future insecurities (4). Thus, savings fall into 3 distinct categories: contractual savings (instalments made for a particular item or paying off a loan/debt), deliberate savings (saving the remaining income after expenditures), and, residual savings (saving money without prior planned expenses) (5).

\section{Applying the concept of maternal mobile money into the Zimbabwean context}

Mobile money, also known as the "mobile wallet," is a technology that is utilised to digitally receive money, store it and pay for expenses through a mobile phone and SIM card (6). Both banks and telecommunications company offer Zimbabwean mobile money services using the Internet and Unstructured Supplementary Service Data (USSD) technology in the format *3digit\# that can be dialled in any mobile phone (7). 
The use of mobile money in Zimbabwe has been studied in socio-economic sectors that include agriculture, finance, and information technology, among others. However, there is a lack of information regarding mobile money for maternal savings, which are imminent. With the proliferation of mobile devices and the massive acceptance of mobile money among the general population (8), there is a need to learn how maternal savings are conducted in Zimbabwe. Maternal health wallets have been implemented in some parts of the world to save money, pay for maternal health expenses and out of pocket payments (OOPS), act as a Rotating Saving and Credit Associations (ROSCAs), teach financial literacy and disseminate health information (9).

Typical examples of mobile money facilities in Zimbabwe's health sector have included the Health Center Management Funds reported in Masvingo Province (10) and EconetHealth (also known as Maisha) (7). The Health Centre Management Funds was a community-based health cover that had various roles, which included paying for waiting mother's shelters, and medical supplies (10). However, because of the hyperinflationary environment in Zimbabwe, some of these community-based health schemes may have died out. EconetHealth was a digital health assistant that relied on the content from $\mathrm{Ada}^{\odot}(11)$, facilitating Econet's mobile subscribers to pay for and receive health messages (including maternal health information) using USSD technology (7).

\section{Health financing in Zimbabwe}

Health financing in Zimbabwe has been often cited as an impediment to health access. Unlike the formative years of the country when universal healthcare was available at no costs to the public health sector, the period from the 1990s to the present has seen a decline in Government spending on healthcare. Hence, there was a time (1990s-2013) when the maternal healthcare system was characterised by user fees, as healthcare providers recovered their service costs by pushing the burden of the costs onto the health consumers (12). Currently, $26 \%$ of health expenses are funded from out of pocket payments, $21 \%$ from the national budget allocation, $16 \%$ through private health insurance schemes, $15 \%$ from foreign aid and the rest from private corporations and nongovernmental organizations (13). 90\% of Zimbabweans do not have health insurance because they are unemployed (14). The $10 \%$ who have health insurance are usually covered by their employers with direct payments made on a regular basis $(14,15)$. Recently, it was found that health insurance covered by the employers is $77.8 \%$ for men (15-49 years), $84.1 \%$ for women (15-49 years), $84.2 \%$ for children (5-17 years), and $86.6 \%$ for children under the age of 5 (15). Other types of health insurance such mutual health organization/community-based health insurance and other privately purchased commercial health insurance receive a lower coverage among the populace (15).

The introduction of the World Bank and CORDAID Results Based Financing (RBF) has seen the scrapping of maternal user fees and the provision of adequate healthcare equipment and supplies for maternal care at district and rural health centres (16). RBF is provided to increase the quality and usage of health facilities using subsidies and negotiations for contracts on the cost of health equipment and materials (16). The rationale of funding the health facilities is based on the performances that are obtained. As a result, user fees have been scraped, and more rural women visit health facilities. For low income populations who reside in the rural areas, RBF acts as both a health insurance and a safety net.

\section{The study}

RoadMApp is a new maternal healthcare mobile wallet (MHMW) facility fused into a geographically enabled transport (geo-mHealth) technology for accessing care. Figure 1 showing an infographic of the proposed RoadMApp, with the MHMW circled $(17,18)$. The arrows on Figure 1 show the direction of service within the RoadMApp intervention. The dotted lines indicate that there are other intermediary services not shown on the diagram but which are potentially important from a design point of view. The proposed design for the RoadMApp mobile wallet is a platform which (a) allows women to save money/crowd source savings for maternity using a mobile service provider of their choice, and (b) a platform which 
communicates the level of saving to date and the reduces travel risk to access maternal healthcare using the total savings to date.

RoadMApp is being implemented in Kwekwe District, Zimbabwe, in 2020. The RoadMApp MHMW is expected to utilise culturally established micro-savings to finance this process (18). It is anticipated that this MHMW will also work as medical savings that will be targeted at persons residing in Kwekwe District (18).

\section{Objectives of the study}

The study explores the feasibility of piloting the RoadMApp MHMW in Kwekwe District, aiming at highlighting: (a) existing strategies and experiences on maternal savings in Kwekwe District, and, (b) examining the implications of household dynamics and, current savings behaviour towards the feasibility of implementing the RoadMApp MHMW in the present and related settings.

\section{Methods}

This study relied on natural interviewing techniques, such as focus group discussions (FGDs) and in-depth informant interviews (IDIIs) (19). FGDs were utilized because they bring together people with similar backgrounds to learn about their motivations, decisions, and priorities (20). The composition of the FGDs varied by age, gender, and position in society. The IDIls were conducted with the flexibility to mix structured questions with prompts for issues of interest (without a particular sequence) (21). The FGDs and IDIls were conducted sequentially and the data from each of the interview methods was integrated during the analysis.

\section{Study site}

Kwekwe District is located in the Midlands province of Zimbabwe. Kwekwe lies within Zimbabwe's gold belt called the "Great Dyke" (see Figure 2). It contains several mining establishments that are mostly located in rural areas. Despite the arid climate in the area, the District is also engaged in communal/subsistence farming and animal husbandry. A large number of the economically active persons in the District are employed in the informal sector. National level statistics applied as proxies, have found that more women (49\%) are employed in sales and services, compared to men (24\%), followed by agriculture, $18 \%$ for women and $25 \%$ for men (2). Men who are employed in skilled manual labour that includes mining make up $25 \%$ (2). The difference between rural and urban areas lies in that urbanites are more likely to engage in sales and services as compared to their rural counterparts who are most likely to engage in agriculture (2). Most of the population has basic literacy skills achieved from either primary or secondary education. For example, primary school completion rates are $90.3 \%$, lower secondary completion rates are $53.7 \%$, and for upper secondary $21.3 \%$ (15). Albeit, higher education is not seen as a priority among several people in the study area, because of limited job opportunities and the high cost of tuition.

\section{Sample}

Typical healthcare clients and health service providers in Kwekwe District were the target population for the FGDs and IDIls. These participants included: pregnant women, women of childbearing age, men, grandparents, and health care providers (nurses and midwives).

\section{Research design}


An exploratory case study research design was considered the best fit for this study's purpose. The case study approach is an in-depth investigation of multiple viewpoints about the complexity of a bounded social phenomenon (e.g., maternal savings) to develop a case description/themes using a wide variety of data (22). Also, a case study is vital to capture the various peculiarities, patterns, and more concealed constraints about a phenomenon (20).

\section{Data collection}

This study utilised non-probability sampling techniques of convenience, quota sampling, and snowballing to collect data. The sampling frame composed of Kwekwe residents who met the inclusion criteria stated above.

Sampling started with the identification of Government-run health facilities in Kwekwe District that offer maternity services. The District's map was representatively stratified into rural, urban and peri-urban community campus points to cover maternal health facilities in the catchment areas. This grouping enabled the research team to collect data from groups/sites that were representative of the demographic composition and theoretical concepts underlying this study. Out of the 49 health facilities in Kwekwe, 2 hospitals (rural and urban), 4 rural health centres, 2 peri-urban, and 2 urban clinics were purposively selected for the study. Convenience sampling was applied to the health facilities within clinics/hospitals to choose these groups. The research team further used quota sampling on participants drawn from the clinics/hospitals. A standardised interview guide was used in both the FGDs and the IDIls (18).

\section{Theoretical framework}

The literature review found that the best theoretical models applying MHMWs in African settings were conducted in Ghana $(23,24)$, Madagascar $(9,25)$, and Zambia $(26)$. These studies guide this paper's conceptual and methodological underpinnings, in particular the adaptation of the Socio-Ecological Model (SEM) presented in the Madagascar study (9). In applying the SEM (16), the researchers have considered the conceptualisation from the predecessor known as Bronfenbrenner's Bioecologicalmodel (27). The model posits that human development is a transactional process in which an individual's development is influenced by his or her interactions with various aspects and spheres of their environment (27). The model considers the multiple levels of influence, that is, the microsystem, which is the individual and context (the pregnant woman, the antenatal clinic, the hospital, home, etc.), the mesosystem (the midwife, other pregnant women, friends, family, community, etc.), exosystem which is a policy and regulatory framework (Ministry of Health and Child Care, mobile service providers, banks, etc.), the macrosystem which refers to dominant institutional patterns of the culture or subculture (e.g. theeconomic, social, educational, legal, and political systems, of which all these systems are embodied).

The paper has operationalised the macrosystem to mean individual-level factors, while the mesosystem and exosystem consider community/institutional level factors and the macrosystem for national-level factors.

\section{Data analysis}

The interviews were transcribed into local languages (Ndebele/Shona), then translated into English by ZNJ, IMD, and a research assistant. After that, the transcriptions were edited to report the participant's accounts and observed behaviours appropriately. ZNJ and IMD conducted first-cycle coding on the transcripts using descriptive and in vivo coding (28) and inputted the data into NVIVO $12^{\odot}$ qualitative analysis software. The coded data was shared with team members for a thematic analysis to identify and interpret the key features of the data vis-à-vis the research objectives (29). The qualitative thematic report was then distributed to the rest of the study team (LC, LM, NN, and PTM) to independently check the consistency of the transcriptions with the emerging themes. 


\section{Results}

A total of 193 people took part in the study through 11 FGDs, 17 IDIls, and 3 community meetings conducted in rural, periurban, and urban settings. Their ages ranged from 18-65 years (see Table 1 for participant distribution).

Table 1: Study participants in Kwekwe District Health Centres (18) 


\begin{tabular}{|c|c|c|c|c|c|c|c|}
\hline CATEGORY & $\begin{array}{l}\text { RURAL } \\
\text { PARTICIPANTS }\end{array}$ & $\begin{array}{l}\text { PERI- } \\
\text { URBAN }\end{array}$ & URBAN & $\begin{array}{l}\text { TOTAL NO. } \\
\text { OF } \\
\text { PARTICIPANTS }\end{array}$ & $\begin{array}{l}\text { AGE } \\
\text { RANGES }\end{array}$ & $\begin{array}{l}\text { EDUCATIONAL } \\
\text { LEVEL }\end{array}$ & $\begin{array}{l}\text { MARITAL } \\
\text { STATUS }\end{array}$ \\
\hline \multicolumn{8}{|l|}{ FGDS } \\
\hline \multirow[t]{3}{*}{$\begin{array}{l}\text { Pregnant } \\
\text { women }\end{array}$} & 14 & 8 & 12 & 34 & $17-38$ & $\begin{array}{l}22 \text { Secondary } \\
\text { school. }\end{array}$ & $\begin{array}{l}26 \\
\text { married; }\end{array}$ \\
\hline & & & & & & $\begin{array}{l}10 \text { Primary } \\
\text { school. }\end{array}$ & $\begin{array}{l}8, \text { not } \\
\text { married }\end{array}$ \\
\hline & & & & & & 2 none & \\
\hline \multirow[t]{4}{*}{ WOCBA } & 20 & - & 15 & 35 & $19-37$ & $\begin{array}{l}27 \text { Secondary } \\
\text { school. }\end{array}$ & $\begin{array}{l}23 \\
\text { married; }\end{array}$ \\
\hline & & & & & & $\begin{array}{l}5 \text { Primary } \\
\text { school. }\end{array}$ & $\begin{array}{l}6 \\
\text { widowed; }\end{array}$ \\
\hline & & & & & & 2 none & 1 single; \\
\hline & & & & & & & $\begin{array}{l}5 \\
\text { divorced }\end{array}$ \\
\hline \multirow[t]{3}{*}{ Elderly women } & 17 & - & 7 & 24 & $53-65$ & $\begin{array}{l}11 \text { Secondary } \\
\text { school. }\end{array}$ & $\begin{array}{l}15 \\
\text { married; }\end{array}$ \\
\hline & & & & & & $\begin{array}{l}9 \text { Primary } \\
\text { school. }\end{array}$ & 3 single; \\
\hline & & & & & & 4 none & $\begin{array}{l}6 \\
\text { widowed }\end{array}$ \\
\hline Spouses & - & - & 8 & 8 & $23-65$ & $\begin{array}{l}8 \text { Secondary } \\
\text { school }\end{array}$ & 8 married \\
\hline \multicolumn{8}{|c|}{ KEY INFORMANTS } \\
\hline \multirow[t]{2}{*}{ Health staff } & 5 & 4 & 1 & 10 & 28- 51 & $\begin{array}{l}10 \text { Secondary } \\
\text { school }\end{array}$ & 8 married; \\
\hline & & & & & & & 2 single \\
\hline Transporters & - & 1 & - & 1 & 42 & $\begin{array}{l}\text { Secondary } \\
\text { school }\end{array}$ & 1 married \\
\hline $\begin{array}{l}\text { Pregnant } \\
\text { women }\end{array}$ & 3 & - & - & 3 & $23-29$ & $\begin{array}{l}\text { Secondary } \\
\text { school }\end{array}$ & 3 married \\
\hline \multirow[t]{2}{*}{ WOCBA } & - & 1 & 1 & 2 & $25-36$ & $\begin{array}{l}\text { Secondary } \\
\text { school }\end{array}$ & 1 married; \\
\hline & & & & & & & $\begin{array}{l}1 \\
\text { divorced }\end{array}$ \\
\hline Spouses & - & - & 1 & 1 & 43 & $\begin{array}{l}\text { Secondary } \\
\text { school }\end{array}$ & 1 married \\
\hline \multicolumn{8}{|c|}{ PARTICIPATORY LEARNING APPROACHES (PLA) } \\
\hline \multirow[t]{3}{*}{$\begin{array}{l}\text { Community } \\
\text { members }\end{array}$} & 74 & - & - & 74 & $27-64$ & $\begin{array}{l}57 \text { Secondary } \\
\text { school. }\end{array}$ & $\begin{array}{l}51 \\
\text { married; }\end{array}$ \\
\hline & & & & & & $\begin{array}{l}12 \text { Primary } \\
\text { school. }\end{array}$ & $\begin{array}{l}19 \\
\text { widowed; }\end{array}$ \\
\hline & & & & & & 5 none & 4 single \\
\hline
\end{tabular}


The sub-themes were organised through the lens of the SEM and sorted with their barriers and enablers towards the RoadMApp MHMW (see Table 2).

Table 2: Socio-Ecological Model of the barriers and enablers towards the RoadMApp MHMW

\begin{tabular}{|c|c|c|c|}
\hline CATEGORY & SUB-THEME & BARRIERS & ENABLERS \\
\hline \multirow{4}{*}{$\begin{array}{l}\text { Individual-level } \\
\text { factors }\end{array}$} & Income/livelihoods; & Low/stable incomes; & Low coverage of health insurance \\
\hline & $\begin{array}{l}\text { Distribution of } \\
\text { income }\end{array}$ & $\begin{array}{l}\text { Women's lack of } \\
\text { autonomy over } \\
\text { finances; }\end{array}$ & \\
\hline & & $\begin{array}{l}\text { No access to mobile } \\
\text { phones; }\end{array}$ & \\
\hline & & Financial illiteracy & \\
\hline \multirow{5}{*}{$\begin{array}{l}\text { Community/ } \\
\text { Institutional level } \\
\text { factors }\end{array}$} & Reducing OOPs; & $\begin{array}{l}\text { No formal follow-ups } \\
\text { on maternal savings; }\end{array}$ & $\begin{array}{l}\text { Maternal layette list is given at FANC } \\
\text { sessions; }\end{array}$ \\
\hline & savings; & Culture/religion; & Existing ROSCAs in communities; \\
\hline & Banking services; & Poor network coverage; & Existing mobile money services \\
\hline & & Banking practices & \\
\hline & & $\begin{array}{l}\text { (high transaction } \\
\text { charges; limited } \\
\text { savings options) }\end{array}$ & \\
\hline National factors & $\begin{array}{l}\text { Poor performing } \\
\text { economy }\end{array}$ & $\begin{array}{l}\text { The high cost of living; } \\
\text { Power outages }\end{array}$ & $\begin{array}{l}\text { Availability of funding for maternal healthcare } \\
\text { (Results-Based Financing, Government } \\
\text { funding) }\end{array}$ \\
\hline
\end{tabular}

\section{Individual-level factors}

Incomes/livelihoods. Mining is the most common source of livelihood in Kwekwe District. It is practiced in established mines as well as in artisanal gold panning shafts. Mostly, it employs men. Women are often engaged in gold panning around riverbeds and the provision of services like food vending for the miners. This was described as an unstable source of income-this potentially compromised women's autonomy in mobilizing money for maternal savings. Furthermore, the women were at risk of being robbed by rival miners and marauding machete-wielding gangs known as "mashurugwi." It was challenging to establish the real family incomes from this study due to the unreliability of sources of revenue. Table 3 summarises estimates of income generated from livelihoods to raise maternal savings. The data on Table 3 was obtained in IDIls as some of the details could not be collected using FGDs. The interview guide with questions on financial strategies is available (18). At the time the data was collected the rate between the USD and the Zimbabwe dollar was USD 1: Z\$10.

Table 3: Estimated income per livelihood to raise maternal savings. 


\begin{tabular}{|ll|}
\hline TYPE OF WORK/LIVELIHOOD & ESTIMATED INCOME \\
\hline Male artisanal mining & USD 50 per week \\
\hline Formal mining & Z\$1,000/ \$100 USD per month \\
\hline Non-financial domestic work & USD 20 per month/Tokens of appreciation \\
\hline Small scale trading & Z\$400/USD 40 per month \\
\hline Market gardening & Z\$400/USD 40 per month \\
\hline Cattle rearing & Z\$2,500/USD 250 per beast \\
\hline Steel Makers company & Z\$300/USD 30 per month \\
\hline Female artisanal mining & Z\$2 per day/ Z\$30 per point \\
\hline Paid domestic work & Z\$20 per day or \$Z100-150 per month \\
\hline Brick-making & Z\$300-600/USD 30-60 per 1000 bricks \\
\hline Prostitution/transactional relationships & As little as Z\$20/USD 2 per encounter \\
\hline
\end{tabular}

The lack of stable incomes/ low incomes from livelihoods was stated as a significant barrier to maternal savings. This is shown in the following excerpt from a conversation about salaries at an urban clinic;

"My husband is a contract worker for one of the big mines in Kwekwe. He earns around Z\$1, 000 (USD 100) per month. He currently has a 3-month contract. There is no guarantee that the contract will be renewed after its expiry. This makes planning for any eventualities difficult because there is no guarantee of job security." (25-35 year-old pregnant woman).

It was common to find that most of the mines and steel factories reportedly did not provide health insurance to their workers and beneficiaries. Also, there was no health insurance in the informal sector. This could be a significant enabler when implementing the MHMW as a large number of the population is excluded from health insurance.

Distribution of income. The distribution of income may affect the mobilisation of maternal savings. Communities attributed the absence of household budgets to financial illiteracy. From the data, it was gathered that men take a large portion of the family income while they distribute little or nothing to women. Most women claimed they had never seen their husband's payslip and could only access what their husband gave them in either cash/groceries. Women viewed men's spending habits to be reckless, for example, spending money on alcohol, gambling, extramarital affairs, and forth. One-woman rural woman spoke about this matter in the following quote:

"My husband never gives me money. I make sure that I do piece jobs when he is at work. All the pregnancies I have carried, I have fended for myself as he has never been a responsible husband." (WoCBA age, 29-35 years).

Accordingly, women had a lack of autonomy in mobilising maternal savings, which made it difficult to plan for pregnancy as they did not make much money in their forms of livelihoods.

Willingness to pay for the MHMW. The participants were questioned how much they would be willing to on the proposed MHMW to determine their willingness to invest as savings into the MHMW to receive maternal health services. The proposed amounts ranged from Z\$10-20 (USD 1-2) per month. These amounts were offered by the participants considering their socio-economic reality and the macroeconomic issues in the country. 


\section{Community/Institutional level factors}

Maternal layette. The introduction of the RBF facility has seen the scrapping of user fees for maternal and child health services. Despite the free services at public health institutions, women still must meet specific requirements to augment shortages at the health facilities. These requirements were separate from the preparations of the usual maternity layette or maternity preparation bag in anticipation of the new-born baby. The baby preparation bag items were costing approximately an equivalent of USD 100 at the time of the study. Additionally, most health institutions expected the women to bring other things that would typically be supplied by the institutions, which included cord clips, methylated spirit, cotton wool, and 5 litres of petrol or diesel for the hospital generators. Women were also expected to bring extra cash for transport in cases of complicated deliveries like caesarean sections and the need for referrals to the next level of care. Women were advised of the requirements during the Focused Antenatal Care (FANC) visits. Health care providers saw the list as a potential enabler for the RoadMApp MHMW as women were informed of items needed for birth preparedness and complications readiness.

A potential bottleneck noted by most participants (including pregnant women) was the inadequacy of following up on the progress in the preparedness of the women as the health providers tended to focus on health education and the physiology of the woman/baby. Women who booked late obtained the maternal layette list at a late stage of their pregnancy. This may have affected their strategies to save for the pregnancy adequately. Nurses struggled to serve this group when the medical supplies were low.

Rotating Saving and Credit Associations (ROSCAs). Saving schemes were typical within the rural and urban areas. These included burial societies and women's clubs for crowdsourcing money on a rotational basis, commonly known as mukando/ukutshayelana. Participants identified ROSCAs as potential enablers for the RoadMApp MHMW because of their availability throughout the District.

Commonly, ROSCAs were utilised for mobilising groceries, monetary savings, funding the full or partial cost of burials/property, and so forth. Crowdsourced funds were preferred because they reduced financial risks, raised capital for income-generating projects, and increased women's security over their money. Rural women were the most active participants of ROSCAs, in most cases, the ROSCAs constituted of 2-40 members. Their subscriptions ranged from Z\$1050 (USD1-5). Savings were determined by the type of the group, income levels, constitution, frequency of sharing the savings, and general household issues (such as consent from their husbands).

Most ROSCAs did not lend to non-members and circulated money among members. To hedge against hyperinflation, some ROSCAs traded their local currency to foreign currency savings (as it was considered more stable than the local currency) or ploughed their money into income-generating projects like rearing cattle, goats, poultry, and piggery and market gardening.

However, there were no ROSCAs dedicated to funding maternal costs fully. FGD participants who were members of the ROSCAs said:

“...for pregnancy it is every person for herself," and;

"...our funds are mainly for assisting in the burial of loved ones, not pregnancy."

However, pregnant women could join a ROSCA and use its services to mobilise funds for their pregnancy. The elderly women noted a high apathy among young women in communal ROSCAs. Elderly women attributed youthful women's apathy to dependence on the permission/funds from husbands/partners who were migrant labourers.

Religion and maternal savings. There are ultra-conservative religious sects such as the Apostolic faith, which has a considerable following across Kwekwe District. Apostolic sects encourage members to use spiritual healing instead of 
medical facilities. Women subscribing to this religious sect deliver in member(s) home(s)/shrines assisted by church midwives.

The sects rely on a different form of ROSCA, in which members contribute towards a fund/gifts to assist the church's pregnant women. A church member stated that members were supposed to know the due date of pregnant women in their church to help in maternal savings. The church would then organise women to visit the expecting mother with gifts (monetary/non-monetary) before and after giving birth.

Reaction to community savings scheme for pregnancy. The consensus was that a maternal saving is ideal as it prevents OOPs, leads to the adequate transportation of pregnant women, and balances home budgets. The participants highlighted their interest to join the RoadMApp MHMW if it was introduced as a ROSCA that was run using the USSD platform through various mobile service providers to cater for areas with poor connectivity. The Midlands State University (host institution of the study) was recommended as the ideal potential manager of the funds from the ROSCA that would be set-up for the MHMW.

Banking/financial system in Kwekwe District. Most of the study sites were rural with no formal banks. The few people with bank accounts are discouraged by the Zimbabwean policies of the $2 \%$ levies charged on every transaction. Accountholders in the rural areas would travel to Kwekwe urban to access their funds. Suffice to mention, travelling to Kwekwe has a lot of challenges as the transporters demanded cash up front. Also, the cash shortages in the country did not guarantee access to scarce cash.

Despite the acceptance of mobile banking in the District, it was criticised for attracting hefty transaction charges. Also, participants from rural areas could not adequately utilise mobile money services due to poor network connectivity and no access to electricity. This adversely affected their day-to-day mobile money transactions and led to a reliance on the use of use cash in the form of local and foreign currency.

\section{National factors}

Economic challenges. The financial difficulties that are being experienced by the country are taking a toll on pregnant women. Over the past two years, Kwekwe District has suffered economic instability just like other parts of the country, characterized by hyperinflation, severe unemployment, and food shortages leading to a low quality of life. Having disposable incomes is, therefore, a considerable challenge.

Results-Based Financing. Across all interviews, participants felt strongly that the RoadMApp MHMW would only be successful if there were funding attached to it. Some even suggested that the RBF (which had introduced free maternity services) could be extended to the RoadMApp intervention. In this way, the RoadMApp MHMW would be more sustainable beyond the pilot and at scale-up.

\section{Discussion}

\section{Existing strategies of financing childbirth}

Income has often been cited as the most robust predictor of overall financing savings (30). However, studies conducted to test this hypothesis are inconclusive as some authors have found that populations with lower incomes may also engage in savings (31). There is a scarcity of evidence suggesting that the hyperinflationary economy in Zimbabwe has lowered the financing of maternal savings (32). This study also demonstrates mixed results showing that maternal savings may be raised through non-financial means such as gifts, livestock, and hand-outs.

Page $11 / 19$ 
Income has some implications when it comes to the implementation of the RoadMApp MHMW. A large number of the population is employed in the informal sector with low/no incomes. This may affect their willingness to pay/consistency in paying for maternal savings. There needs to be some flexibility in the amounts payable, and the timing of the payments and subsidies/interest are given to women who save more money. For example, percentage interests may be added based on the amount on the account. However, the funds that communities are willing to pay are quite low, considering the current healthcare costs (an average of USD 100) and inflation. The proposed for the willingness to pay in this study (USD 1-2), are well below figures found in other local studies (USD 5.43) and cannot adequately cover maternal health costs (14). This implies that the RoadMApp MHMW would have to rely heavily on subsidies from Government or donor funds to reduce the number of subscribers paying OOPs. Research has proven that when OOPs are higher than the amount paid for health financing, subscribers are deterred from paying subscriptions.

\section{Current savings behaviour}

Current savings behaviour may be explained through the sub-themes of financial illiteracy, culture, religion, and the usage of mobile money services. This is consistent with the postulations made by an earlier study that looked into the determinants of savings behaviour in Zimbabwe (33). Other local studies have found that religion affects the savings for healthcare or access to health insurance, where some sects exclude their members from seeking help from health facilities (14).

Financial illiteracy. An overarching sub-theme found in the results is the lack of financial literacy among the study participants. For instance, participants mentioned that household incomes earned in gold mining/panning are often misused and unequally distributed within the household. The lack of financial literacy regarding maternal savings may be caused by a high dependency syndrome and the need for instant gratification (34). This is because Zimbabwe is traditionally a socialist economy that provides subsidised healthcare (35). Perhaps this may explain the spending habits of men and women in both rural and urban scenarios, which results in a low saving culture for maternal health financing and living from "hand to mouth" with the income earned.

Some studies implementing MHMWs have given pregnant women dedicated cards to purchase maternal materials and pay for healthcare costs (36). This has been effective in effecting financial discipline among households.

Use of banking/mobile money services. Kwekwe District has low usage of banking facilities for savings. This is a macrolevel issue that results from Zimbabweans' low saving culture rooted from the economic woes of the past decades. Hence, there is little confidence in the financial sector. This is worsened by "low levels of income, lack of variety of attractive savings plans, low-interest rates on savings, policy inconsistencies" (37), as well as the unavailability of cash in the economy. As a result, the participants prefer to keep some money in hand instead of digital balances. This finding is consistent with recent Zimbabwean studies establishing that large amounts of transactions from the economy are banked informally $(7,28)$.

Therefore, it may be challenging for the intended MHMW to leverage maternal savings as there are macroeconomic issues that need to be addressed by the Government of Zimbabwe. What can be done in the meantime is to rely on existing structures such as the mobile banking systems and ROSCAs in communities. Furthermore, Zimbabwean women's low use of financial services/mobile money may be due to their low income (39).

ROSCAs. To mitigate their financial exclusion, women in the study rely on the ROSCAs, to engage in contractual and deliberate savings with others to create extra savings and access loans. ROSCAs are a strategy used by women to avoid spousal interference with monetary savings (40). Therefore, ROSCAs are an effective means of countering inequalities created within the household and financial institutions. Also, entrusting the management of the MHMW to an external body relieves the community of settling issues of trust and security (41). However, it is uncertain if all community-level ROSCAs

Page 12/19 
will fit into the RoadMApp MHMW. This is because each ROSCA may have different objectives, the demographic composition of members (gender, ages, incomes, and so forth), constitution, socio-political systems, and savings (foreign currency, cash, livestock, and so forth).

\section{Limitations Of The Study}

One drawback of qualitative research is that it cannot make specific predictions but can help to understand the underlying and often mundane practices of the participants. For instance, confidential information could not be obtained from the participants. Hence, predictions cannot be made on average savings made for pregnancy, when savings began, frequency of savings amongst participants, and whether the savings are adequate to cover maternal costs. Studies that have obtained this information have been successful because of the use of randomization and anonymity imposed by quantitative techniques (26). Hence, it is inconclusive whether women who book late/do not attend FANC have no savings at all. For example, evidence from a study conducted in Zambia suggests that when there are constant price hikes, there are no significant differences between the OOPs of maternal women who save and those who do not (26). This could be the same case with Zimbabwe, where prices constantly change. Further research should dig deeper into this assumption.

Furthermore, at the time of collecting data, the RoadMApp MHMW did not have a prototype in the study area. Hence, the study has underreported the digital literacy skills of communities in using an MHMW and whether it will integrate with current saving habits and level of education (literacy and ICT skills). This is unlike similar studies that have piloted MHMW and assessed their implementation among different groups (42). Future studies on RoadMApp or any other MHMW may have to take note of this limitation and conduct their independent assessments to close this gap.

\section{Recommendations}

A quantitative study with a self-administered questionnaire/survey would ideally collect personal information such as education levels, incomes, distribution of income and percentiles for savings, usage of mobile money and digital literacy among other variables to make statistical analyses for decision making before implementing the project. The results of this study can then be used to provide information rich narratives. The ROADMApp team can consider using a sequential mixed design (QUAL $\rightarrow$ QUAN) and rely on triangulation to validate, integrate or converge these findings together with quantitative ones (43).

\section{Conclusion}

This paper highlighted the current strategies and experiences about maternal savings in Kwekwe District. It also observed the consequences of the population's savings behaviour towards the feasibility of implementing RoadMApp, a maternal healthcare mobile wallet (MHMW) service. In the context of hyperinflation, ancillary factors such as financial literacy, usage of the banking system/mobile money, culture, and religion help to understand the psychosocial reasons why participants in Kwekwe District engage in maternal savings. There are macro-level issues that may become potential barriers to the successful implementation of this MHMW. However, specific attention should be paid to individual and community/institutional level factors such as subsidies/interests on amounts saved, enforcing financial discipline, building local level mobile network infrastructure, and relying on locally available persons/systems.

\section{Declarations}

\section{Availability of data and materials}

Page 13/19 
All sources of information used in this qualitative analysis, including community responses, are archived by the Place Alert Labs and may only be available with individual permissions as governed by the Medical Research Council of Zimbabwe.

\section{Contributions}

Dr. Zibusiso Nyathi Jokomo and Israel Dabengwa contributed to writing the draft manuscript. Dr. Zibusiso Nyathi Jokomo, Israel Dabengwa, Professor Laurine Chikoko, Liberty Makacha, and Dr. Prestige Tatenda Makanga made substantive contributions to copy-editing the first complete version of the manuscript and were involved together with all the other authors in the interpretation of the findings. All authors revised the manuscript and copy-edited the final submission version. All the authors were also involved in revising the manuscript critically for valuable intellectual content. All authors read and approved the final manuscript. Dr. Zibusiso Nyathi Jokomo, Israel Dabengwa, and Doctor Prestige Tatenda Makanga made substantive contributions in summarizing all the content in the paper.

\section{Ethics declarations}

\section{Ethical approval and consent to participate}

Ethical approval for the study was obtained from the Institutional Review Board of the Midlands State University (the institution which received the grant) under Science and Technology/PT Makanga. Thereafter, ethics approval was sought from the Medical Research Council of Zimbabwe (an overarching body that under administers health/medical research in Zimbabwe) under Ref No: MRCZ/A/246. Both ethics approval included both written and verbal consent (to be used in the case of illiterate persons) to collect data.

We got permission to conduct the study from the Ministry of Health, Provincial and District Medical Directors, Health staff in charge of local health facilities, Local authorities, Chiefs and local leaders and all participants. We explained the purpose of the study to all the participants using a written consent forms and verbatim in local languages. Verbal informed consent was audiotaped after explaining the purpose of the study and the participants recorded on the fieldnotes. We received both verbal and written informed consent from the participants without coercion. Participants gave consent for the use an audio recorder to capture the proceedings of the discussions. Separate registers were kept for both written and informed consent. The data collected was anonymized to ensure confidentiality. We served refreshments after the discussions.

\section{Funding}

The proposed intervention is funded by Grant Challenges Canada under grant Number ST-POC-1807-12966 - Midlands State University. The response seeks to address delays in accessing care by linking pregnant women to locally available transport options and means of saving for maternity.

\section{Guarantor}

Dr. Prestige Tatenda Makanga and Dr. Zibusiso Nyati-Jokomo

\section{Acknowledgements}

This work is part of the RoadMApp - Improving access to maternal care funded by Grant Challenges Canada, Grant Number ST-POC-1807-12966 - Midlands State University awarded to Dr. Prestige Tatenda Makanga of Midlands State University, Zimbabwe. The work was supported by the Place Alert Labs, Faculty of Science and Technology, Midlands State University, and the Research and Postgraduate Studies Office at Midlands State University. We acknowledge valuable insights received from all members of the Place Alert Labs at Midlands State University in Zimbabwe. 
Not applicable

\section{Conflicting interests}

The authors declare that none of the authors have any actual or potential conflict of interest and competing interests about this publication.

\section{Abbreviations}

FANC - Focused Antenatal Care

FGD - Focus Group Discussions

IDII - In-depth Informant Interviews

MHMW - Maternal Health Mobile Wallet

OOPs - Out-Of-Pocket Payments

PLA - Participatory Learning Approaches

RBF - Results-Based Financing

ROSCAs - Rotating Saving and Credit Associations

SEM - Socio-Ecological Model

USSD - Unstructured Supplementary Service Data

WOCBA - Women of Childbearing Age

\section{References}

1. Rockers P, Chiu C, Hangoma P. Saving during pregnancy in Zambia. New Haven: Innovation for Poverty Action; 2018.

2. Zimbabwe National Statistics Agency. Zimbabwe demographic and health survey 2015: final report [Internet]. Rockville, Maryland: Zimbabwe National Statistics Agency (ZIMSTAT) and ICF International.; 2016 [cited 2020 Sep 30]. Available from: https://dhsprogram.com/pubs/pdf/FR322/FR322.pdf

3. World Health Organization (WHO). From Millenium to Sustainable Development Goals: global strategy for women, children and adolescents' health 2016-2030 [Internet]. 2017 [cited 2020 Feb 24]. Available from: https://www.who.int/life-course/partners/global-strategy/en/

4. Lunt PK, Livingstone SM. Psychological, social and economic determinants of saving: comparing recurrent and total savings. J Econ Psychol. 1991;12(4):621-41.

5. Katona G. Psychological economics. Washington, DC: Elsevier; 1975.

6. Mutsonziwa K, Maposa OK. Mobile money - a catalyst for financial inclusion in developing economies: a case study of Zimbabwe using FinScope survey data. GIS Bus. 2016;12(4):45-56.

7. Zhou M, Herselman M, Coleman A. USSD technology a low cost asset in complementing public health workers' work processes. In: Ortuño F, Rojas I, editors. Bioinformatics and Biomedical Engineering. Cham: Springer International Publishing; 2015. p. 57-64.

8. Murendo C, Mutsonziwa K. Financial literacy and savings decisions by adult financial consumers in Zimbabwe. Int J Consum Stud [Internet]. 2017 Jan;41(1):95-103. Available from: http://doi.wiley.com/10.1111/ijcs.12318 
9. Muller N, McMahon SA, de Neve JW, Funke A, Bärnighausen T, Rajemison EN, et al. Facilitators and barriers to the implementation of a Mobile Health Wallet for pregnancy-related health care: A qualitative study of stakeholders' perceptions in Madagascar. PLoS One. 2020;15(1):1-15.

10. Bishi J, Shamu A, van Dijk JH, van Stam G. Community engagement for eHealth in Masvingo, Zimbabwe. In: 1 st International Multi Disciplinary Conference - 23-25 August 2017, Lusaka Zambia [Internet]. Lusaka: International Multi Disciplinary Conference; 2017 [cited 2020 Sep 30]. p. 1-6. Available from:

https://www.researchgate.net/publication/323747587_Community_Engagement_for_eHealth_in_Masvingo_Zimbabwe

11. Ada. About us [Internet]. [cited 2020 Nov 6]. Available from: https://ada.com/about/

12. Mutopo Y. Rethinking health care financing models: the case of Zimbabwe's health sector. MSc. Thesis (Published). University of Cape Town; 2017.

13. Government of Zimbabwe. Zimbabwe national health accounts 2015. Harare, Zimbabwe: Ministry of Health and Child Welfare; 2016.

14. Muchabaiwa L, Chigusiwa L, Bindu S, Mudavanhu V, Damiyano D, Mushanyuri BE. Feasibility and sustainability of community based health insurance in rural areas: case study of Musana, Zimbabwe. Expert J Financ. 2017;5:73-85.

15. Zimbabwe National Statistics Agency (ZIMSTAT). 2019 Multiple Indicator Cluster Survey (MICS). Harare, Zimbabwe: Zimbabwe National Statistics Agency; 2019.

16. Sithole A. Results based financing in Zimbabwe: any changes in the health delivery system? J Soc Welf Hum Rights. 2013;1(1):36-46.

17. Place Alert Labs. RoadMApp [Internet]. 2019 [cited 2019 Oct 24]. Available from: https://ww5.msu.ac.zw/pals/research/roadmapp/

18. Nyati-Jokomo Z, Dabengwa IM, Makacha L, Nyapwere N, Dube YP, Chikoko L, et al. RoadMApp: a feasibility study for a smart travel application to improve maternal health delivery in a low resource setting in Zimbabwe [Internet]. Vol. 20, BMC Pregnancy and Childbirth. 2020 [cited 2020 Sep 30]. p. 501. Available from:

https://bmcpregnancychildbirth.biomedcentral.com/articles/10.1186/s12884-020-03200-7

19. Chambers R. Ideas for development. London: Institute of Development Studies; 2005.

20. Berg BL, Lune H. Qualitative research methods for the social sciences. 9th ed. Harlow: Pearson; 2017.

21. Merriam SB, Tisdel EJ. Qualitative research: a guide to design and implementation. 4th ed. Hoboken, New Jersey: Josey-Bass/Wiley; 2016.

22. Yin RK. Case study research and applications: design and methods. 6th ed. Los Angeles: SAGE Publications, Inc.; 2018.

23. Laar AS, Bekyieriya E, Isang S, Baguune B. Assessment of mobile health technology for maternal and child health services in rural Upper West Region of Ghana [Internet]. Vol. 168, Public Health. Elsevier Ltd; 2019 [cited 2020 Sep 30]. p. 1-8. Available from: https://doi.org/10.1016/j.puhe.2018.11.014

24. Clark S, Paul M, Aryeetey R, Marquis G. An assets-based approach to promoting girls' financial literacy, savings, and education [Internet]. Vol. 68, Journal of Adolescence. Elsevier; 2018 [cited 2020 Sep 30]. p. 94-104. Available from: https://doi.org/10.1016/j.adolescence.2018.07.010

25. Muller N, Emmrich MPF, Rajemison EN, de Neve J-W, Barnighausen T, Knauss S, et al. A mobile health wallet for pregnancy-related health care in Madagascar: mixed-methods study on opportunities and challenges. Vol. 7, JMIR mHealth and uHealth (ejournal). 2019.

26. Chiu C, Scott NA, Kaiser JL, Ngoma T, Lori JR, Boyd CJ, et al. Household saving during pregnancy and facility delivery in Zambia: a cross-sectional study. Health Policy Plan. 2019;34(February):102-9.

27. Bronfenbrenner U. Toward an experimental ecology of human development. Am Psychol [Internet]. 1977;32(7):513-31. Available from: http://content.apa.org/journals/amp/32/7/513 
28. Saldaña J. The coding manual for qualitative researchers. Los Angeles: SAGE Publications Inc.; 2009.

29. Clarke V, Braun V. Thematic analysis. J Posit Psychol. 2017 May 4;12(3):297-8.

30. Chikoko L, Roux P Le, Canicio D. Microeconometric analysis of the determinants of savings behaviour in Zimbabwe: 2009-2012. Int J Bus Manag. 2013;8(10):159-68.

31. Van Schie RJG, Donkers B, Dellaert BGC. Savings adequacy uncertainty: driver or obstacle to increased pension contributions? J Econ Psychol [Internet]. 2012;33(4):882-96. Available from:

http://dx.doi.org/10.1016/j.joep.2012.04.004

32. Jennings L, Yang F, Otupiri E, Akinlo A, Okunlola M, Hindin M. Association of household savings and expected future means with delivery using a skilled birth attendant in Ghana and Nigeria: a cross-sectional analysis. Matern Child Health J. 2016;21:85-95.

33. Laurine C, Roux P Le, Canicio D. Microeconometric Analysis of the Determinants of Savings Bahaviour in Zimbabwe: 2009-2012. Int J Bus Manag. 2013;8(10):159-68.

34. Chauke HM. The determinants of household saving: the South African Black middle class perspective. [Internet]. MSc. Thesis (Pubished). University of Pretoria; 2011. Available from: http://repository.up.ac.za/dspace/bitstream/handle/2263/25807/dissertation.pdf?sequence=1\&isAllowed=y

35. Meisenhelder T. The decline of socialism in Zimbabwe. Mediterr Q. 1994;21(4):83-101.

36. Borghi J, Ensor T, Somanathan A, Lissner C, Mills A. Mobilising financial resources for maternal health. Lancet. 2006;368(9545):1457-65.

37. Chikoko L. Antidote to promoting a savings culture: Zimbabwe post dollarisation. Int J Econ Commer Manag. 2015;III(12):609-17.

38. FinMark Trust. Measuring progress: financial inclusion in SADC - 2019 [Internet]. Johannesburg: FinMark Trust; 2019 [cited 2020 Apr 25]. Available from: http://finmark.org.za/wp-content/uploads/2019/08/ME_Report_2019.pdf

39. Marumbwa J. Exploring the moderating effects of socio-demographic variables on consumer acceptance and use of mobile money transfer services (mmts) in Southern Zimbabwe. Am J Ind Bus Manag. 2014;04(02):71-9.

40. Anderson S, Baland J. The economics of ROSCAS and intrahousehold resource allocation. Q J Econ. 2002;117(3):963-94.

41. Marumbwa J. An analysis of the factors influencing consumers' adoption of mobile money transfer services (MMTs) in Masvingo urban, Zimbabwe. Br J Econ Manag Trade. 2013;3(4):498-512.

42. Rothstein JD, Jennings L, Moorthy A, Yang F, Gee L, Romano K, et al. Qualitative assessment of the feasibility, usability, and acceptability of a mobile client data app for community-based maternal, neonatal, and child care in rural Ghana. Int J Telemed Appl. 2016;2016:1-15.

43. Teddlie C, Tashakkori A. Overview of contemporary issues in mixed methods research. Handb Mix Methods Soc Behav Res [Internet]. 2010;1-41. Available from: http://scholar.google.com/scholar?

$\mathrm{hl}=$ en\&btnG=Search\&q=intitle:Overview+of+contemporary+issues+in+mixed+methods+research\#0

\section{Figures}




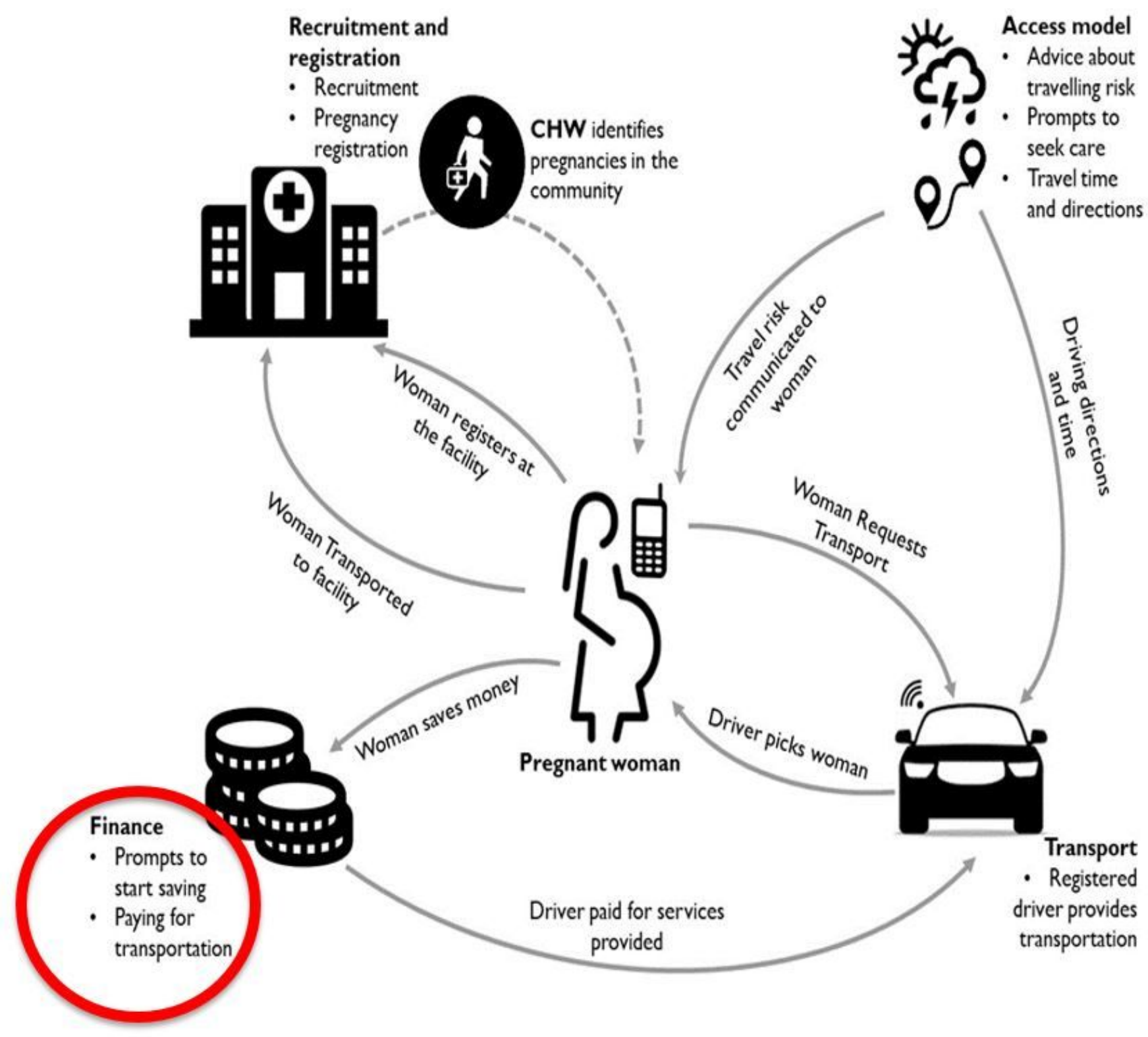

Figure 1

showing an infographic of the proposed RoadMApp MHMW (17) 


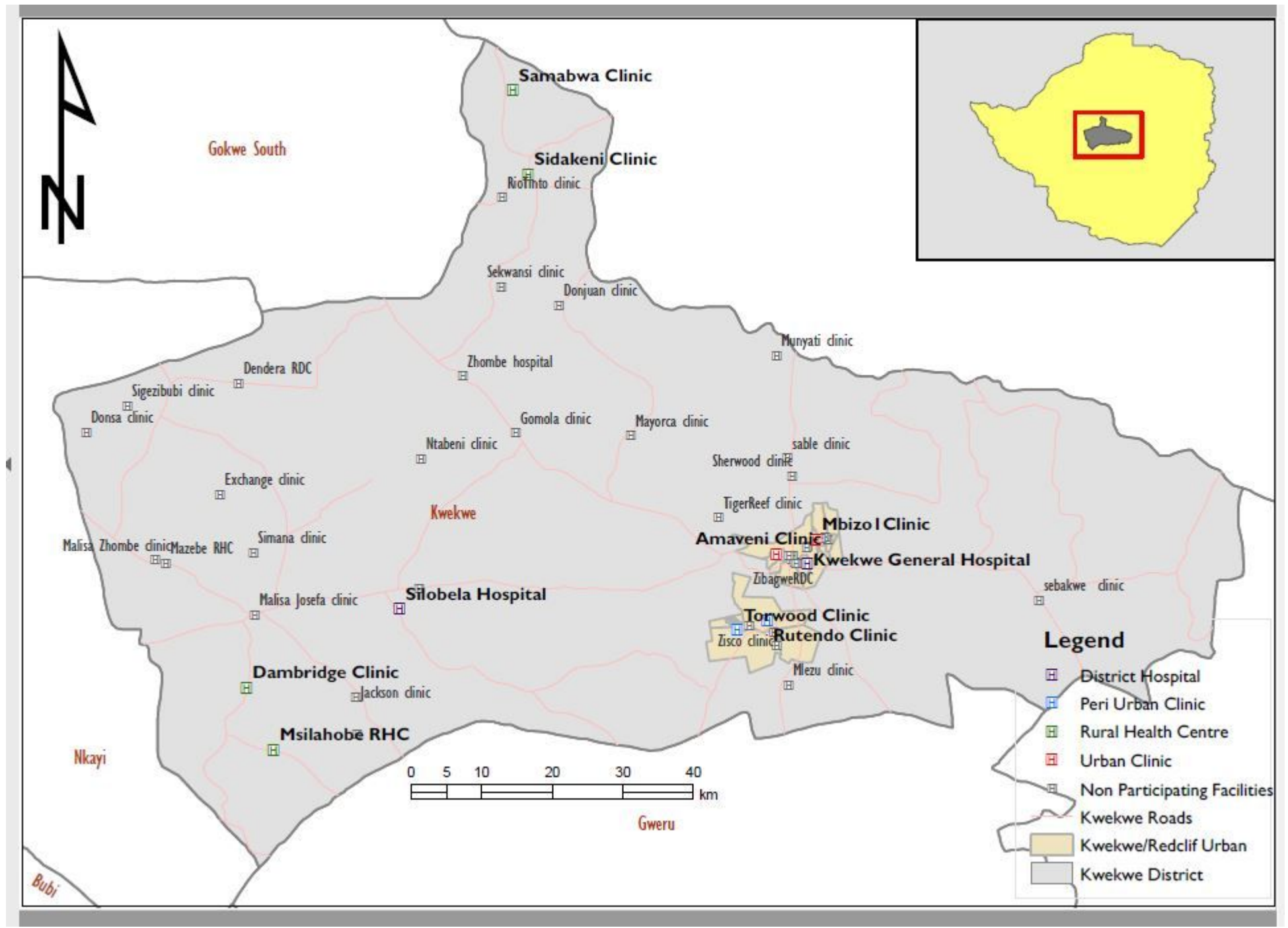

\section{Figure 2}

showing a map of the data collection sites Note: The designations employed and the presentation of the material on this map do not imply the expression of any opinion whatsoever on the part of Research Square concerning the legal status of any country, territory, city or area or of its authorities, or concerning the delimitation of its frontiers or boundaries. This map has been provided by the authors.

\section{Supplementary Files}

This is a list of supplementary files associated with this preprint. Click to download.

- RoadMAppCOREQChecklist.pdf 